\title{
BMJ Open Prevalence, risk factors and associations of primary Raynaud's phenomenon: systematic review and meta-analysis of observational studies
}

\author{
Rozeena Garner, ${ }^{1}$ Rakesh Kumari, ${ }^{1}$ Peter Lanyon, ${ }^{1}$ Michael Doherty, ${ }^{1,2}$ \\ Weiya Zhang ${ }^{2}$
}

To cite: Garner R, Kumari R, Lanyon $\mathrm{P}$, et al. Prevalence, risk factors and associations of primary Raynaud's phenomenon: systematic review and meta-analysis of observational studies. BMJ Open 2015;5:e006389. doi:10.1136/bmjopen-2014006389

- Prepublication history and additional material is available. To view please visit the journal (http://dx.doi.org/ 10.1136/bmjopen-2014006389).

Received 15 August 2014 Revised 11 December 2014 Accepted 30 January 2015

CrossMark

\section{ABSTRACT}

Objective: To systematically review the literature with regard to the prevalence, incidence, risk factors and associations of primary Raynaud's phenomenon (PRP). Method: A systematic review of the literature of observational studies for PRP was undertaken using five electronic databases. Any studies reporting prevalence, incidence and risk factors of PRP were collected. Relative risk or $\mathrm{OR}$ and $95 \% \mathrm{Cl}$ were extracted or calculated to present the association between risk factors and PRP. Random effects model was used to pool the results.

Results: 33 articles assessing a total of 33733 participants were included in this analysis (2 cohort, 17 cross-sectional and 14 case-control studies). The pooled prevalence of PRP was $4.85 \%(95 \% \mathrm{Cl} 2.08 \%$ to $8.71 \%$ ) in the general population. The pooled annual incidence of PRP was $0.25 \%$ (95\% Cl $0.19 \%$ to $0.32 \%)$. Risk factors and associations for PRP included female gender $(0 \mathrm{R}=1.65,95 \% \mathrm{Cl} 1.42$ to 1.91), family history ( $\mathrm{OR}=16.6,95 \% \mathrm{Cl} 7.44$ to 36.8$)$, smoking (OR=1.27, 95\% $\mathrm{Cl} 1.06$ to 1.53$)$, manual occupation (OR=2.66 $95 \% \mathrm{Cl} 1.73$ to 4.08$)$, migraine (OR=4.02, 95\% Cl 2.62 to 6.17 ), cardiovascular disease $(\mathrm{OR}=1.69,95 \% \mathrm{Cl} 1.22$ to 2.34$)$ and marital status (married, $\mathrm{OR}=0.60,95 \% \mathrm{Cl} 0.43$ to 0.83 ). The definition of PRP varied considerably between studies. Conclusions: This is the first systematic review of the prevalence, incidence, risk factors and associations of PRP. Further study using uniform strict criteria for the condition is required to confirm these findings,

particularly the possible association with cardiovascular disease.

\footnotetext{
${ }^{1}$ Department of

Rheumatology, Queens Medical Centre, Nottingham, UK

${ }^{2}$ Department of Academic Rheumatology, University of Nottingham, Nottingham, UK

Correspondence to Dr Weiya Zhang; weiya.zhang@nottingham.ac. uk
}

\section{Strengths and limitations of this study}

- This is the first meta-analysis of the literature for the global epidemiology of primary Raynaud's phenomenon (PRP).

- The prevalence and incidence of PRP in different countries were estimated. Female gender, positive family history, smoking and migraines were found to be the major risk factors for PRP.

- The lack of original data restricted an adequate estimation of the age effect on PRP.

- Different definitions of PRP handicapped a comparison between countries.

occlusion. ${ }^{1}$ Further criteria have been suggested to distinguish primary RP (PRP) from secondary RP, which include detail regarding symptom duration, negative autoimmune serology, normal serum inflammatory markers and capillaroscopy and the clinical absence of any underlying disease. ${ }^{1-4}$ Use of colour charts to aid diagnosis has also been used. ${ }^{45}$ Despite this, there is no unifying definition that is used worldwide for PRP.

There have been a number of studies performed in various countries reporting the prevalence of RP. The reported prevalence ranges from less than $1 \%$ (in men) and up to $20 \%$ (in women) depending on definitions and population selected. ${ }^{6}$ In contrast, few studies have examined the incidence of PRP, and the true burden of PRP in the general population remains unclear. PRP is thought to be more common in women, particularly when it develops at a young age. ${ }^{7}$ There are also reports of a hereditary component and links with other vasospastic conditions such as migraine. ${ }^{8-11}$ It is uncertain whether other comorbidities or risk factors particularly related to vascular diseases such as ischaemic heart disease and/or smoking have an association with PRP. 
The primary objective of this study was to perform a systematic review of observational studies to summarise the literature with regard to the prevalence, incidence and risk factors/associations of PRP. The secondary objective was to examine the current definitions used to define PRP worldwide.

\section{METHODS}

Literature search-data sources and search strategy

A comprehensive systematic literature search was undertaken in June 2011 and rerun in October 2014 using five databases: MEDLINE, EMBASE, CINAHL, AMED and PubMed. The search terms for "Raynauds" or "Raynauds disease" were combined with the terms "epidemiology", "prevalence", "risk" or "incidence" to generate the citations (see online supplementary appendix 1 for full details of search strategy). "Cross sectional", "case-control" or "cohort" studies and "systematic review" were also applied for types of studies.

Abstracts were reviewed and the full papers were sought where abstracts were felt to be relevant. Any duplicate articles were excluded (figure 1 and appendix 1 and 2). Where there was difficulty in article retrieval, the authors were contacted via email. The literature search and abstract review was completed by RG and validated by WZ. Reference lists of the review articles were also examined for relevant studies.

\section{Inclusion and exclusion criteria}

Inclusion criteria: studies reporting the prevalence and/ or incidence of PRP; studies reporting potential risk factors associated with PRP; studies reporting human data on PRP in people of any age; studies in any language ( 4 articles required translation-1 Japanese, 1 Turkish, 1 French, 1 Italian).

Exclusion criteria (figure 1): studies assessing treatment of PRP; studies involving participants with RP secondary to other diseases; studies assessing RP in a specific occupation, for example, people using vibration tools; unpublished material, case reports, editorials, letters or reviews.

\section{Data extraction and quality assessment}

Study characteristics including age range, gender ratio and total number of participants in the study were documented. The study design, country, setting (ie, hospital
Figure 1 Flow chart diagram showing results of systematic literature search.

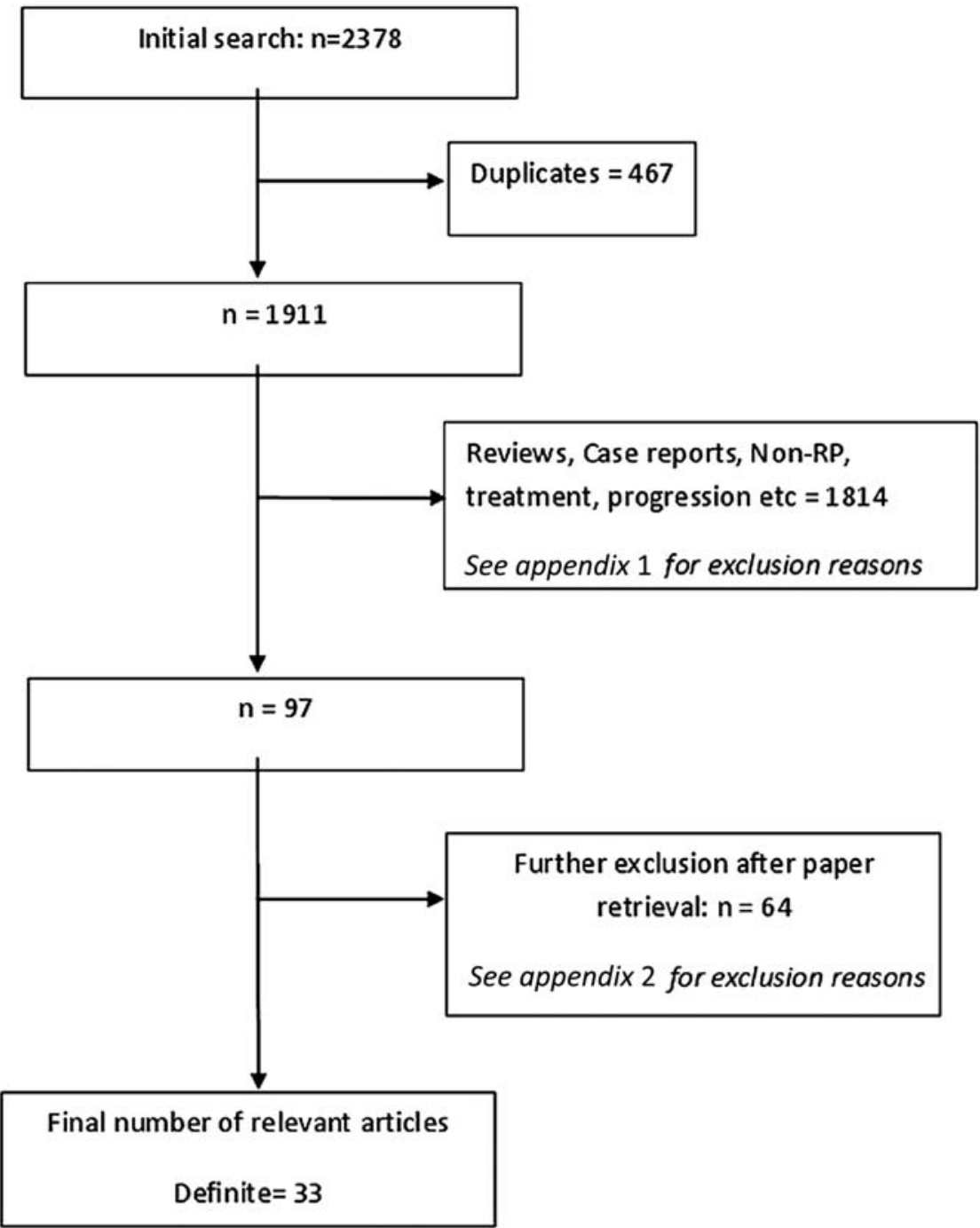


or community based) were also assessed and noted. If more than one article used the same study population, the article where the data were felt to be presented most clearly was used in the study. The definition of PRP and instruments used to confirm the condition were also documented. The number of cases of PRP out of the number of people studied in a certain time in the general population was documented as unadjusted crude prevalence. Incidence figures were documented if the number of new cases of PRP in the population at risk studied over a given period of time was stated.

Individual OR, relative risk (RR) or $\mathrm{HR}$ and their $95 \%$ CI were extracted or calculated for the following:

- Constitutional: age, gender

- Environmental: employment, education, marital status and sex hormone medications

- Genetic: family history in 1st degree relatives

- Associations: smoking, alcohol, cardiovascular disease (CVD) and migraine

All studies were reviewed by RG to assess study quality and for data extraction and were validated by WZ. An independent reviewer (RK) assessed a random selection of articles to ensure quality of data extraction. Study quality was assessed according to study design (cohort, cross-sectional and case-control), setting (community or hospital), sample size, case definition, exposure definition, confounding factors and adjustment. Quality scoring for studies was not performed as it is not possible or fair to assign equal weight to different quality aspects related to the study. However, current consensus standards of reporting meta-analysis of observational studies in epidemiology ${ }^{12}$ were followed, and subgroup/sensitivity analysis was undertaken to examine the changes of the estimate according to different quality aspects.

\section{Statistical analysis}

Individual data for prevalence and incidence were derived from the original report either directly or indirectly from the information provided in each study. The pooled proportion was calculated as the back transform of the weighted mean of the transformed proportion, using inverse arcsine variance weights for the fixed effects model and DerSimonian and Laird ${ }^{13}$ weights for the random effects model. ${ }^{14}$ Cumulative incidence and 95\% CI were transformed into incidence rate data (ie, incidence per 100 person-years) and pooled incidence rate was estimated. Individual data for $\mathrm{OR}, \mathrm{RR}$ and $\mathrm{HR}$ were pooled to present the overall relative risk of all observational studies, as well as separately for each specific risk measure or study design as appropriate. Random effects mode was used to pool the data. ${ }^{15}$ Heterogeneity was examined using Forest plots, Cochran $\mathrm{Q}$ tests and $\mathrm{I}^{2}$ statistic as a measure for inconsistency due to chance. ${ }^{16}{ }^{17}$ Publication bias was assessed using funnel plots and Eggers test or the Harbord test if the number of studies included in the meta-analysis was too small $(\leq 4) .{ }^{18}$ All analyses were undertaken using StatsDirect V.2.7.9.
RESULTS

\section{Study characteristics}

In total, 2378 citations were found in the initial literature search. All 467 duplicates were removed and 1878 citations were excluded as they did not meet the inclusion criteria (figure 1). The final number of studies available for analysis was 33 (33 733 participants). There were two cohort studies $^{1920}$ (1 632 participants), 17 cross-sectional studies $^{6}{ }^{21-36}$ (25 797 participants) and 14 case-control studies $^{7-11} \quad 37-45$ (6 304 participants; table 1). Data for incidence and prevalence were taken from cohort and cross-sectional studies, respectively. Data for risk factors were taken from all studies as long as the results were reported.

Age ranges across different study designs were as follows: case-control (16-79 years), cohort (18-81 years), cross-sectional (12-84 years). Sixty-seven per cent of the studies involved participants recruited in a communitybased setting. The majority of studies were conducted in Europe (18) ${ }^{6} 9192224262729303233$ 35-37 3941-43 or the USA (10), ${ }^{8} 1011202123384044$ however, other countries of origin included Japan (2), ${ }^{25}{ }^{28} \mathrm{New}$ Zealand (1) ${ }^{34}$ and Israel (1).$^{45}$ One comparison study included participants from the USA and France. ${ }^{31}$

Participants were surveyed by means of phone, face-to-face interview and/or postal questionnaire. Twenty-six studies included a physical examination that also included blood testing (including serology), nailfold capillaroscopy and use of colour chart/photographs (table 1).

Ten studies used specific criteria to define PRP (3 studies $^{8} 2132$ Allen and Brown; ${ }^{1} 3^{9} 36 \quad 37$ LeRoy and Medsger $^{2} ; 4^{6} 2233{ }^{34}$ UK Scleroderma Study Group $^{4}$ ). The remaining studies used a combination of cold sensitivity, varying degrees of colour change and sensory symptoms via questionnaire or interview to define PRP. Colour charts or photographs to indicate colour change were used in 12 studies $^{6} 791019202528293133 \quad 35$ and nailfold capillaroscopy was performed as part of the examination in 10 studies. $^{8}{ }^{9} 193136373941-43$ In 15 studies, blood testing including serology and/or inflammatory markers was performed. ${ }^{6} 8911243033363739-44$

Studies with clear definition of PRP or clear exclusion criteria for secondary RP were categorised as 'definite PRP' in this study. Studies with less clear definition of PRP were categorised as 'possible PRP'. Studies with clear definition of secondary RP were excluded.

\section{Prevalence of PRP}

The overall prevalence for definite PRP varied from $1.6 \%$ to $7.2 \%$ in six cross-sectional studies in the general population (women: 2.1-15.8\% and men: 0.8-6.5\%). ${ }^{21} 2325272933$ The pooled prevalence was $4.85 \%$ (95\% CI $2.08 \%$ to $8.71 \%$; figure 2), with $5.74 \%$ (95\% CI $2.74 \%$ to $9.75 \%$ ) in women and $4.12 \%$ (95\% CI $1.60 \%$ to $7.74 \%$ ) in men. We used the Harbord test to detect publication bias (1.59, 92.5\% CI -21.6 to 24.8; $\mathrm{p}=0.87$ ). The overall prevalence for possible PRP ranges from $3.98 \%$ to $12.7 \%$ (women: $4.5-$ $17.9 \%$ and men: $3.4-7.2 \%)$ in three cross-sectional 
Table 1 Characteristics of studies

\begin{tabular}{|c|c|c|c|c|}
\hline & Cohort & Cross-sectional & Case-control & All studies \\
\hline Number of studies & 2 & 17 & 14 & 33 \\
\hline Number of participants & 1632 & 25797 & 6304 & 33733 \\
\hline Age & $18-81$ & $12-84$ & $16-79$ & $12-84$ \\
\hline \multicolumn{5}{|l|}{ Setting } \\
\hline Community based & 2 & 14 & 5 & 21 \\
\hline Hospital based & 0 & 2 & 9 & 11 \\
\hline Community and hospital & 0 & 1 & 0 & 1 \\
\hline \multicolumn{5}{|l|}{ Region of study } \\
\hline USA & 1 & 2 & 7 & 10 \\
\hline Europe & 1 & 11 & 6 & 18 \\
\hline France and USA & 0 & 1 & 0 & 1 \\
\hline Japan & 0 & 2 & 0 & 2 \\
\hline New Zealand & 0 & 1 & 0 & 1 \\
\hline Israel & 0 & 0 & 1 & 1 \\
\hline \multicolumn{5}{|l|}{ Diagnosis* } \\
\hline Questionnaire & 0 & 5 & 2 & 7 \\
\hline Questionnaire+examination & 2 & 9 & 12 & 23 \\
\hline
\end{tabular}

studies. ${ }^{26} 3435$ The prevalence in specific populations varies depending on the studies (table 2).

In six studies assessing the general population we found the lowest prevalence of PRP in Japan, with an overall prevalence of $1.6(2.1 \%$ in women, $1.1 \%$ in men). ${ }^{25}$ Highest overall prevalence figures were found in the USA with a median prevalence of $7.5 \%$ (7.8\% in women, $5.8 \%$ in men). ${ }^{21}{ }^{23} \mathrm{~A}$ study from France also showed high prevalence figures of $11.75 \%$ in women and $6.3 \%$ in men (median values; ${ }^{31}$ table 3 ).
Five studies reported prevalence of PRP by age. ${ }^{628-30} 34$ Three did not find any age-related prevalence. ${ }^{6} \quad 28 \quad 30$ Purdie $e t a \hat{l}^{34}$ reported a higher prevalence of PRP in younger compared to older age groups, whereas Fraenkel et $a \hat{l}^{8}$ reported higher prevalence in older age groups in men (adjusted $\mathrm{OR}=2.3$, 95\% CI 1.0 to 5.2 highest vs lowest tertile) but not in women (adjusted $\mathrm{OR}=0.9,95 \%$ CI 0.4 to 1.6). Jones et $a l^{29}$ also showed a slight increase in prevalence by age in yearly increments between ages 12 and 15 years.
Figure 2 Forest plot showing the pooled prevalence of definite primary Raynaud's phenomenon for five general population studies.
Forest plot for heterogeneity, $\mathrm{I}^{2}=98.2 \%(95 \% \mathrm{Cl}=97.6,98.6)$

$\mathrm{p}$ for heterogeneity $<0.0001$

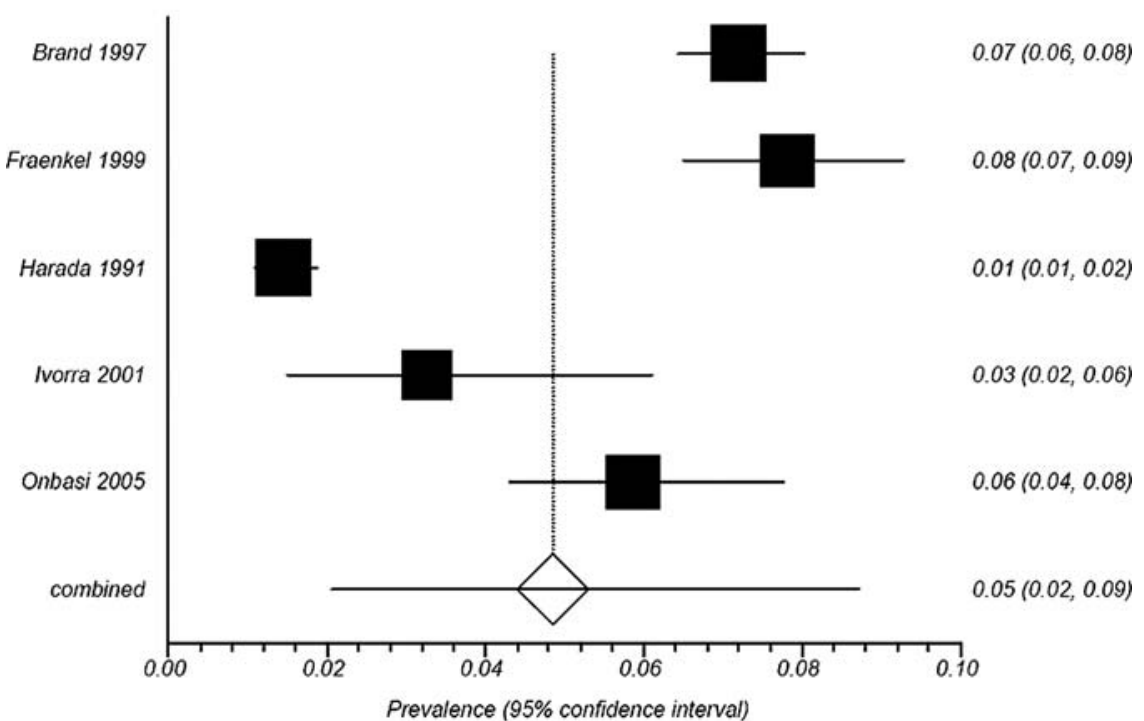


Table 2 Prevalence of primary Raynaud's phenomenon in 17 studies

\begin{tabular}{|c|c|c|c|c|c|c|c|c|}
\hline \multirow[b]{2}{*}{ First author } & \multirow[b]{2}{*}{ Country } & \multirow[b]{2}{*}{ Setting } & \multirow{2}{*}{$\begin{array}{l}\text { Sample } \\
\text { size }\end{array}$} & \multirow{2}{*}{$\begin{array}{l}\text { Age mean } \\
\text { (SD)/range }\end{array}$} & \multirow{2}{*}{ Female (\%) } & \multicolumn{3}{|c|}{ Prevalence } \\
\hline & & & & & & Overall (\%) & Female (\%) & Male (\%) \\
\hline \multicolumn{9}{|c|}{ Prevalence of definite primary Raynaud's phenomenon in general population studies } \\
\hline Brand (1997) & Boston, USA & Com & 4182 & 51.8 & 52.2 & 7.2 & 7.8 & 6.5 \\
\hline Fraenkel (1999) & Boston, USA & Com & 1525 & 53.9 & 52.5 & 7.8 & 9.6 & 5.8 \\
\hline Harada (1991) & Ehime, Japan & Hosp & 3873 & $20-70$ & 51.6 & 1.6 & 2.1 & 1.1 \\
\hline Ivorra (2001) & Valencia, Spain & Com & 276 & 54.4 & 74.3 & 3.3 & 3.4 & 2.8 \\
\hline \multirow[t]{5}{*}{ Maricq $(1997)^{\star}$} & South Carolina, USA & Com & $2086 / 432$ & $18+$ & NS & NS & 3.4 & 0.8 \\
\hline & Toulon, France & Com & $1998 / 189$ & $18+$ & NS & NS & 11.4 & 2.8 \\
\hline & Nyons, France & Com & $1996 / 345$ & $18+$ & NS & NS & 5.8 & 6.2 \\
\hline & Grenoble, France & Com & $2069 / 272$ & $18+$ & NS & NS & 12.1 & 6.4 \\
\hline & Tarentaise, France & Com & $2000 / 296$ & $18+$ & NS & NS & 15.8 & 6.3 \\
\hline Onbasi (2005) & Van, Turkey & Com & 768 & $29.2(10.4)$ & 46.6 & 5.9 & 7.0 & 4.9 \\
\hline \multicolumn{9}{|c|}{ Prevalence of possible primary Raynaud's phenomenon in general population studies } \\
\hline Heslop (1983) & Southampton, UK & Com & 450 & $20-59$ & 50.9 & 12.7 & 17.9 & 7.2 \\
\hline Purdie (2009) & New Zealand & Com & 234 & $18+$ & 56.8 & 11.5 & 17.3 & 4.0 \\
\hline Sahin (2003) & Van, Turkey & Hosp & 251 & 28.9 & 53.4 & 3.98 & 4.5 & 3.4 \\
\hline \multicolumn{9}{|c|}{ Prevalence of primary Raynaud's phenomenon in single gender only population studies } \\
\hline Leppert (1987) & Vasteras, Sweden & Com & 2705 & $18-59$ & 100 & - & 15.6 & - \\
\hline Olsen (1978) & Copenhagen, Denmark & Com & 67 & $21-50$ & 100 & - & 22.4 & - \\
\hline Tzilalis (2011) & Athens, Greece & Com & 3912 & 18-28 & 0 & - & - & 0.18 \\
\hline \multicolumn{9}{|c|}{ Prevalence of primary Raynaud's phenomenon in studies using hospital personnel } \\
\hline Cakir (2008) & Edirne, Turkey & Com & 1414 & 27.2 & 59.3 & 3.6 & 4.8 & 1.9 \\
\hline Gallo (1994) & Milan, Italy & Com & 1920 & $15-84$ & 68 & 4.2 & 4.5 & 3.9 \\
\hline Iwata (1987) & Japan & $\mathrm{C} \& \mathrm{H}$ & 1470 & $18-59$ & 56.8 & 4.8 & 6.5 & 2.5 \\
\hline Voulgari (2000) & Ioannina, Greece & Com & 500 & $33.7(6.2)$ & 77.8 & 5.2 & 6.4 & 0.9 \\
\hline \multicolumn{9}{|c|}{ Prevalence of primary Raynaud's phenomenon in studies assessing children } \\
\hline Jones (2003) & Manchester, UK & Com & 716 & $12-15$ & 50.8 & 14.9 & 17.6 & 12.2 \\
\hline
\end{tabular}

Incidence of primary Raynauds phenomenon

Only two studies reported incidence rates. ${ }^{19}{ }^{20}$ Carpentier et al reported an annual incidence rate of $0.25 \%(95 \%$ CI $0.17 \%$ to $0.33 \%$ ), with $0.24 \%$ in women and $0.26 \%$ in men and Suter et al reported a 7-year incidence of $1.87 \%$ (2.2\% in women and $1.5 \%$ in men), which was converted to an annual incidence rate of $0.26 \%$ (95\% CI $0.17 \%$ to $0.39 \%$ ). The pooled annual incidence rate of these two studies was therefore $0.25 \%$ (95\% CI $0.19 \%$ to $0.32 \%$ ).

\section{Risk factors and associations}

In 18 studies (23 197 participants), there was a positive association between female gender and PRP (OR=1.65, 95\% CI 1.42 to 1.91$){ }^{6} 79$ 20-29 33-35 3744 Family history, assessed in two studies looking at first-degree relatives, also had a positive significant association with PRP $(\mathrm{OR}=16.6$, 95\% CI 7.44 to 36.8$).{ }^{8}{ }^{9}$ No significant association was found with education beyond primary school age $\mathrm{a}^{637}$ (table 4). Manual occupation (not including vibration

Table 3 Regional variation of prevalence of primary Raynaud's phenomenon for general population studies including prevalence rates for males and females

\begin{tabular}{|c|c|c|c|c|c|}
\hline \multirow[b]{2}{*}{ Country } & \multirow[b]{2}{*}{ Number of studies } & \multirow[b]{2}{*}{ Number of participants } & \multicolumn{3}{|c|}{ Prevalence (\%) } \\
\hline & & & Male & Female & Total \\
\hline USA * & 3 & 6139 & 5.8 & 7.8 & 7.5 \\
\hline France* $^{*}$ & 1 & 1102 & 6.3 & 11.75 & - \\
\hline Spain & 1 & 276 & 2.8 & 3.4 & 3.3 \\
\hline Turkey & 1 & 768 & 4.9 & 7.0 & 5.9 \\
\hline Japan & 1 & 3873 & 1.1 & 2.1 & 1.6 \\
\hline Total & 6 & 12158 & & & \\
\hline
\end{tabular}

*Median values calculated for prevalence. The US gender figures include data from Maricq et $a{ }^{\beta 1}$ (France and the USA). Total US prevalence figure includes data from two US-only studies. 
Table 4 Risk factors of Raynaud's phenomenon

\begin{tabular}{|c|c|c|c|c|c|}
\hline Risk factor & $\begin{array}{l}\text { Number of studies } \\
\text { (Number of } \\
\text { participants) }\end{array}$ & Pooled OR & $95 \% \mathrm{Cl}$ & $\mathrm{I}^{2} \%(95 \% \mathrm{Cl})^{\star}$ & p (heterogeneity) \\
\hline Female & 18 (23 197) & 1.65 & 1.42 to 1.91 & $17.2(0$ to 53$)$ & 0.25 \\
\hline Family history of RP & $2(421)$ & 16.6 & 7.44 to 36.8 & - & 0.34 \\
\hline Marital status $†$ & $4(2650)$ & 0.60 & 0.43 to 0.83 & $16.9(0$ to 73$)$ & 0.31 \\
\hline Education $\ddagger$ & $2(891)$ & 1.52 & 0.89 to 2.59 & - & 0.24 \\
\hline Manual occupation & 1 (3 873) & 2.66 & 1.73 to 4.08 & - & - \\
\hline Smoking & $9(8501)$ & 1.27 & 1.06 to 1.53 & $6.2(0.8$ to 57.1$)$ & 0.38 \\
\hline Alcohol & $2(4967)$ & 0.33 & 0.02 to 5.37 & - & $<0.0001$ \\
\hline Migraine§ & $6(2595)$ & 4.02 & 2.62 to 6.17 & 35.9 (0 to 73.6$)$ & 0.17 \\
\hline Diabetes & $1(1525)$ & 0.51 & 0.2 to 1.27 & - & - \\
\hline Hypertension & $2(1711)$ & 1.00 & 0.67 to 1.48 & - & 0.46 \\
\hline Hypercholesterolaemia & $1(1525)$ & 0.86 & 0.53 to 1.40 & - & - \\
\hline Coronary heart disease & $1(81)$ & 0.58 & 0.1 to 3.31 & - & - \\
\hline Cardiovascular diseaseף & 1 (3 442) & 1.69 & 1.22 to 2.34 & - & - \\
\hline Helicobacter pylori* & $2(265)$ & 0.91 & 0.51 to 1.63 & - & 0.07 \\
\hline $\mathrm{CP}$ & $2(268)$ & 0.69 & 0.34 to 1.38 & - & 0.88 \\
\hline Oestrogen replacement therapy†† & $2(1242)$ & 2.34 & 1.42 to 3.84 & - & 0.81 \\
\hline \multicolumn{6}{|c|}{ 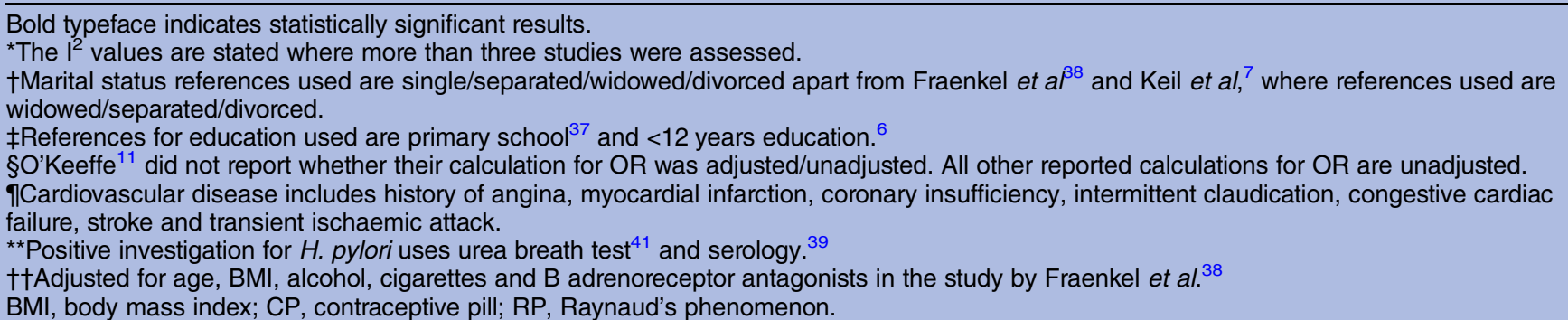 } \\
\hline
\end{tabular}

tool use) had an OR of 2.66 (95\% CI 1.73 to 4.08$)$ in one study of 3873 participants. ${ }^{25}$ In four studies, being married was associated with a lower risk of PRP with OR of 0.60 (95\% CI 0.43 to 0.83 ) compared with being single/ divorced/widowed. ${ }^{6-7} 2337$ Smoking was found to have an association in nine studies giving a pooled OR of 1.27 (95\% CI 1.06 to 1.53). ${ }^{79-112022233244}$ Alcohol use, ${ }^{23} 44$ participants with positive Helicobacter pylori investigations $^{39} 41$ and those with conditions such as diabetes, ${ }^{23}$ hypertension $^{11} 23$ and hypercholesterolaemia ${ }^{23}$ did not have a significant association with PRP.

Migraine had a positive significant association with a pooled OR of $4.02(95 \%$ CI 2.62 to 6.17$)$ in six studies. ${ }^{6} \quad 9-11 \quad 22 \quad 45$ One study of 3442 participants reported a positive association of CVD with PRP with an OR of 1.69 (95\% CI 1.22 to 2.34$).{ }^{44}$ CVD in this study included a history of ischaemic heart disease, intermittent claudication, congestive cardiac failure and cerebrovascular disease. A single study using 81 participants did not show a positive significant association of coronary heart disease with PRP. ${ }^{40}$

A positive association was found in participants taking oestrogen replacement therapy alone in two studies with an OR of 2.34 (95\% CI 1.42 to 3.84$){ }^{23} 38$ However, no significant association was found in combined oestrogen and progesterone replacement therapy ${ }^{38}$ in postmenopausal women or in contraceptive pill (CP $)^{10}{ }^{11}$ use in two other studies. A study by Smyth et $a l^{9}$ looking at allele frequencies of known polymorphisms of candidate vasoactive mediator genes (eNOS, BKRG, ET01 and ETA receptor genes) did not show any association. Shemirani et $a l^{42}$ looked at clotting factors in participants with PRP and found a significant association with methyltetrahydrofolate reductase $\mathrm{C} 677 \mathrm{~T}$ mutations $(\mathrm{OR}=0.4,95 \%$ CI 0.2 to $0.9)$ but no difference in other thrombosis-associated alleles (FVLeiden, prothrombin G20210 A).

\section{DISCUSSION}

This is the first meta-analysis of the literature for the prevalence, incidence, risk factors and associations of PRP. Overall, the pooled mean prevalence of PRP in the general population was $4.85 \%$ (95\% CI $2.08 \%$ to $8.71 \%$; figure 2) and the mean incidence was $0.25 \%$ (95\% CI $0.17 \%$ to $0.33 \%$ ) per annum. ${ }^{19}$ Major risk factors/associations of PRP include female gender, family history of PRP, migraine, smoking, CVD, manual occupation, oestrogren replacement therapy and possibly, marital status (table 4).

Variations in prevalence were observed between countries (table 3), though this could reflect use of different diagnostic criteria rather than real differences in prevalence. The heterogeneity of prevalence figures may also reflect the differences in the way the studies were conducted, the selection of participants (eg, age and gender) and the disease definition. All studies (except for Maricq et $a l^{31}$ ) demonstrate a higher prevalence of 
PRP in women. This may be due to a relationship with female hormones as two studies found an association between PRP and use of oestrogen replacement therapy alone, ${ }^{23} 38$ although no association was found between combined oestrogen and progesterone replacement or the CP. ${ }^{10-11}{ }^{38}$ In contrast, prevalence of PRP does not increase with age in five published studies with a wide age range of participants from 12 up to 84 years. ${ }^{62-30} 34$ This accords with the clinical observation that PRP usually starts in teenage years and that later development, which is far less common, is characteristic of secondary RP. While the former may be driven predominantly by genetic risk factors, later onset 'primary' Raynaud's may be predominantly influenced by environmental exposures such as vascular microtrauma from manual usage and vibrating tools. In terms of other environmental factors we did find a weak negative association between marital status and PRP with an OR of 0.60 (95\% CI 0.43 to 0.83 ) in those that are married versus single/ separated/widowed/divorced. ${ }^{6-7} 23{ }^{37}$ However, there is no plausible biological explanation for this and the reported data may not be free from confounding bias.

The association of CVD and autoimmune disease is well documented and thought to be due to accelerated atherosclerosis as a result of chronic inflammation, treatment such as glucocorticoids as well as the traditional risk factors for CVD. ${ }^{4-52} \mathrm{~A}$ link between CVD and PRP has been shown in only one study ${ }^{44}$ and the reason for this association is not known. It is unlikely to be due to an inflammatory process or related to medication, and with PRP having predominance for the female population and onset at a young age, it is not clear if traditional cardiovascular risk factors play a part. However, smoking was found to have a positive association with PRP in our study (OR=1.27, 95\% CI 1.06 to 1.53 ). It is well known that smoking is one of the three (smoking, hypertension and hyperlipidaemia) main risk factors for cardiovascular and cerebrovascular disease.$^{53-59}$ Smoking may have the same risk factor for PRP and CVD. Whether smoking causes PRP first and then CVD is an interesting question that deserves further research. More interestingly, we found a very strong association between migraine and PRP (OR=4.02, 95\% CI 2.62 to 6.17$)$. It has been previously shown that migraine is due to a cascade of vascular and neural events. ${ }^{46}{ }^{47}$ However, a review by Rosamund suggested that migraine was not shown to be linked with coronary heart disease but possibly shares a common underlying pathophysiology with RA and other vasospastic disorders such as variant angina. ${ }^{60}$ It is thought there may be other factors that could affect the underlying mecanism for these vasospastic conditions as episodes occur at different times with differing precipitants. ${ }^{62}{ }^{63}$ Further study may help clarify whether PRP is a benign vasospastic disorder or whether there is underlying pathology affecting the vascular wall associated with traditional risk factors seen in CVD.
There are a number of caveats to this study. Firstly, it was striking that there was no uniform definition for diagnosis of PRP. Only 39\% of studies looking at prevalence had a precise definition for PRP, thereby reducing the number of studies we used to assess pooled prevalence. It is possible that the variation in definition of PRP together with the way participants were recruited and assessed may have led to underestimation or overestimation of the true prevalence of PRP in the general population. We feel that an amalgamation of the generally more commonly used definitions would ensure that the diagnosis is clear by assessing symptoms, using a colour chart or photographs for confirmation of colour change and carefully exclude underlying conditions including checking for digital infarcts/ulceration, nailfold capillaroscopy, and assessing autoimmune screen and inflammatory markers. Secondly, as our objective was to specifically examine the epidemiology of PRP, a large proportion of studies were excluded because they focused on secondary Raynaud's phenomenon, especially related to connective tissue diseases and vibration white finger. In addition, we also excluded studies that looked at investigation or treatment of PRP. This left only a small number of studies to assess. From the studies included, there was a great deal of variation in the population of participants used. Nine of the 17 studies used investigated participants in the general population, whereas the remainder examined specific populations such as single gender, children or hospital/medical personnel. Furthermore, there was considerable variation in the risk factors addressed in each study and this may have affected the significance and association, or lack of association between the risk factors and PRP. We tried to extract as many risk factors from each study as possible to use in our analysis. In the future, a larger multinational population study may help us to get a better understanding of the disease. This would be particularly useful if standardised criteria were used to include participants in the studies, using strict definition for PRP (as mentioned previously), and data were collected in a similar fashion assessing a wide variety of possible risk factors (particularly related to CVD and vasospastic disorders) for more accurate data analysis.

\section{CONCLUSION}

This first systematic review summarises the burden of PRP in the general population using published literature. It is not a rare condition (prevalence $4.85 \%$ and annual incidence $0.25 \%$ ). It starts at a young age, is more common in women, and associates with a family history and with smoking. In addition, people with PRP are four times more likely to have migraine than those without this condition.

Acknowledgements The authors sincerely thank Joanna Ramowski and Helen Richardson for article retrieval and support. They specially thank Anu Suokas, Karin Tatsumoa, Professor Tiraje Truncer, Ana Valdes and Maggie Wheeler for language translation. 
Contributors WZ, MD, PL and RG were involved in study conception and design. RG, RK and WZ were involved in acquisition of the data. RG and WZ were involved in statistical analysis. RG, WZ, MD and PL were involved in analysis and interpretation of the data. RG, WZ, MD and PL were responsible for manuscript preparation and final approval of the manuscript.

Competing interests None.

Provenance and peer review Not commissioned; externally peer reviewed.

Data sharing statement No additional data are available.

Open Access This is an Open Access article distributed in accordance with the Creative Commons Attribution Non Commercial (CC BY-NC 4.0) license, which permits others to distribute, remix, adapt, build upon this work noncommercially, and license their derivative works on different terms, provided the original work is properly cited and the use is non-commercial. See: http:// creativecommons.org/licenses/by-nc/4.0/

\section{REFERENCES}

1. Allen E, Brown G. Raynaud disease: a critical review of minimal requisites for diagnosis. Am J Med Sci 1932;183:187-200.

2. LeRoy E, Medsger T. Raynaud's phenomenon: a proposal for classification. Clin Exp Rheumatol 1992;10:485-8.

3. Bowling J, Dowd P. Raynaud's disease. Lancet 2003;361:2078-80.

4. Brennan $\mathrm{P}$, Silman A, Black C, et al. Validity and reliability of three methods used in the diagnosis of Raynaud's phenomenon. The UK Scleroderma Study Group. Br J Rheumatol 1993;32:357-61.

5. Maricq $\mathrm{H}$, Weinrich M. Diagnosis of Raynaud's phenomenon assisted by colour charts. J Rheumatol 1988;15:454-9.

6. Voulgari P, Alamanos Y, Papazisi D, et al. Prevalence of Raynaud's phenomenon in a healthy Greek population. Ann Rheum Dis 2000;59:206-10.

7. Keil J, Maricq H, Weinrich M, et al. Demographic, social and clinical correlates of Raynaud phenomenon. Int J Epidemiol 1991;20:221-4.

8. Freedman R, Mayes M. Familial aggregation of primary Raynaud's disease. Arthritis Rheum 1996;39:1189-91.

9. Smyth AE, Hughes AE, Bruce IN, et al. A case-control study of candidate vasoactive mediator genes in primary Raynaud's phenomenon. Rheumatology (Oxford) 1999;38:1094-8.

10. O'Keeffe S, Tsapatsaris N, Beetham W. Association between Raynaud's phenomenon and migraine in a random population of hospital employees. J Rheumatol 1993;20:1187-8.

11. O'Keeffe S, Tsapatsaris N, Beetham W. Increased prevalence of migraine and chest pain in patients with primary Raynaud disease. Ann Intern Med 1992;116(12 Pt 1):985-9.

12. Stroup D, Berlin J, Morton S, et al. Meta-analysis of observational studies in epidemiology (Moose) group. JAMA 2000;283:2008-12.

13. DerSimonian R, Laird N. Meta-analysis in clinical trials. Control Clin Trials 1986;7:177-88.

14. Stuart A, Ord JK. Kendall's advanced theory of statistics. 6th edn. London: Edward Arnold, 1994.

15. Whitehead A, Whitehead J. A general parametric approach to the meta-analysis of randomised clinical trials. Stat Med 1991;10:1665-77.

16. Gavaghan D, Moore R, McQuay $H$. An evaluation of homogeneity tests in meta-analyses in pain using simulations of individual patient data. Pain 2000;85:415-24.

17. Higgins J, Thomspon S, Deeks J, et al. Measuring inconsistency in meta-anlyses. BMJ 2003;327:557-60.

18. Egger M, Davey Smith G, Schneider M, et al. Bias in meta-anlysis detected by a simple, graphical test. BMJ 1997;315:629-34.

19. Carpentier P, Satger B, Poensin D, et al. Incidence and natural history of Raynaud phenomenon: a long-term follow-up (14years) of a random sample from the general population. $J$ Vasc Surg 2006;44:1023-8.

20. Suter L, Murabito J, Felson D, et al. The incidence and natural history of Raynaud's phenomenon in the community. Arthritis Rheum 2005;52:1259-63.

21. Brand F, Larson M, Kannel W, et al. The occurrence of Raynaud's phenomenon in a general population: the Framingham Study. Vasc Med 1997:2:296-301.

22. Cakir N, Pamuk O, Donmez S, et al. Prevalence of Raynaud's phenomenon in healthy Turkish medical students and hospital personnel. Rheumatol Int 2008;29:185-8.
23. Fraenkel L, Zhang $\mathrm{Y}$, Chaisson CF, et al. Different factors influencing the expression of Raynaud's phenomenon in men and women. Arthritis Rheum 1999;42:306-10.

24. Gallo E, Bianchi E, Motta A, et al. [The incidence of Raynaud's phenomenon in 1920 residents in Milan]. [Italian] Incidenza de fenomeno di Raynaud in 1920 residenti in Milano. Minerva Cardioangiol 1994;42:65-71.

25. Harada N, Ueda A, Takegata S. Prevalence of Raynaud's phenomenon in Japanese males and females. J Clin Epidemiol 1991;44:649-55.

26. Heslop J, Coggon D, Acheson E. The prevalence of intermittent digital ischaemia (Raynaud's phenomenon) in a general practice. $J$ R Coll Gen Pract 1983;33:85-9.

27. Ivorra J, Perales J, Carballido C, et al. Prevalence of Raynaud's phenomenon in general practice in the East of Spain. Clin Rheumatol 2001;20:88-90.

28. Iwata H, Makimo S, Miyashita K. [Prevalence of Raynaud's phenomenon in individuals not using vibrating tools]. Sangyo Igaku 1987;29:500-3.

29. Jones G, Herrick A, Woodham S, et al. Occurrence of Raynaud's phenomenon in children ages 12-15 years: prevalence and association with other common symptoms. Arthritis Rheum 2003;48:3518-352.

30. Leppert J, Aberg H, Ringqvist I, et al. Raynaud's phenomenon in a female population: prevalence and association with other conditions. Angiology 1987;38:871-7.

31. Maricq $\mathrm{H}$, Carpentier $\mathrm{P}$, Weinrich $\mathrm{M}$, et al. Geographic variation in the prevalence of Raynaud's phenomenon: a 5 region comparison. $J$ Rheumatol 1997;24:879-89.

32. Olsen N, Nielsen S. Prevalence of primary Raynaud phenomena in young females. Scand J Clin Lab Invest 1978;38:761-4.

33. Onbasi K, Sahin I, Onbasi O, et al. Raynaud's phenomenon in a healthy Turkish population. Clin Rheumatol 2005;24:365-9.

34. Purdie G, Harrison A, Purdie D. Prevalence of Raynaud's phenomenon in the adult New Zealand population. $N Z M e d J$ 2009;122:55-62.

35. Sahin I, Onbasi K, Onbasi O, et al. Raynaud's phenomenon in healthy population who admitted to the hospital in Van Region, Turkey [Turkish] Van Yoresinde Hastaneye Basvuran Saglikli Populasyonda Raynaud Fenomeni. Ondokuz Mayis Universitesi Tip Dergisi 2003;20:73-7.

36. Tzilalis V, Panagiotopoulos N, Papatheodorou G, et al. Prevalence of Raynaud's phenomenon in young Greek males. Clin Rheumatol 2011;30:57-9.

37. De Angelis R, Salaffi F, Grassi W. Health-related quality of life in primary Raynaud phenomenon. J Clin Rheumatol 2008;14:206-10.

38. Fraenkel L, Zhang Y, Chaisson C, et al. The association of estrogen replacement therapy and the Raynaud phenomenon in postmenopausal women. Ann Intern Med 1998;129:208-12.

39. Herve F, Cailleux N, Benhamou Y, et al. [Helicobacter pylori prevalence in Raynaud's disease]. [French] Prevalence des infections a Helicobacter pylori au cours de la maladie de Raynaud. Rev Med Interne 2006;27:736-41.

40. Koh K, Kim S, Lee K, et al. Does prevalence of migraine and Raynaud's phenomenon also increase in Korean patients with proven variant angina? Int J Cardiol 1995;51:37-46.

41. Savarino V, Sulli A, Zentilin $P$, et al. No evidence of an association between Helicobacter pylori infection and Raynaud phenomenon. Scand J Gastroenterol 2000;35:1251-4.

42. Shemirani A, Szomjak E, Balogh E, et al. Polymorphism of clotting factors in Hungarian patients with Raynaud's. Blood Coagul Fibrinolysis 2011;22:56-9.

43. Susol E, MacGregor A, Barrett J, et al. A two-stage, genome-wide screen for susceptibility loci in primary Raynaud's phenomenon. Arthritis Rheum 2000;43:1641-6.

44. Suter L, Murabito J, Felson D, et al. Smoking, alcohol consumption, and Raynaud's phenomenon in middle age. Am J Med 2007;120:264-71.

45. Zahavi I, Chagnac A, Hering R, et al. Prevalence of Raynaud's phenomenon in patients with migraine. Arch Intern Med 1984;144:742-4

46. Shoenfeld $Y$, Gerli R, Doria A, et al. Accelerated atherosclerosis in autoimmune rheumatic diseases. Circulation 2005;112:3337-47.

47. Tyrrell P, Beyene J, Feldman B, et al. Rheumatic disease and carotid intima-media thickness: a systematic review and meta-analysis. Arterioscler Thromb Vasc Biol 2010;30:1014-26.

48. Schoenfeld S, Kasturi S, Costenbader K. The epidemiology of atherosclerotic cardiovascular disease among patients with SLE: a systematic review. Semin Arthritis Rheum 2013;43:77-95.

49. Peters M, Symmons D, McCarey D, et al. EULAR evidence-based recommendations for cardiovascular risk management in patients 
with rheumatoid arthritis and other forms of inflammatory arthritis. Ann Rheum Dis 2010;69:325-31.

50. Gabriel S, Michaud K. Epidemiological studies in incidence, prevalence, mortality, and comorbidity of the rheumatic diseases. Arthritis Res Ther 2009;11:229.

51. Lévy L, Fautrel B, Barnetche T, et al. Incidence and risk of fatal myocardial infarction and stroke events in rheumatoid arthritis patients. A systematic review of the literature. Clin Exp Rheumatol 2008;26:673-9.

52. Avina-Zubieta J, Choi H, Sadatsafavi M, et al. Risk of cardiovascular mortality in patients with rheumatoid arthritis: a meta-analysis of observational studies. Arthritis Rheum 2008;59:1690-7.

53. Burns D. Epidemiology of smoking-induced cardiovascular disease. Prog Cardiovasc Dis 2003;46:11-29.

54. De Backer G. Risk factors and prevention of cardiovascular disease: a review. Dialogues Cardiovasc Med 2008;13:83-99.

55. O'Donnell M, Xavier D, Liu L, et al. Risk factors for ischaemic and intracerebral haemorrhagic stroke in 22 countries (the INTERSTROKE study): a case-control study. Lancet 2010;376:112-23.

56. JBS3 Board. Joint British Societies' consensus recommendations for the prevention of cardiovascular disease (JBS3). Heart 2014;100 (Suppl 2):ii1-ii67.

57. [No authors listed]. Joint British recommendations on prevention of coronary heart disease in clinical practice. British Cardiac Society, British Hyperlipidaemia Association, British Hypertension Society, endorsed by the British Diabetic Association. Heart 1998;80 (Suppl 2):S1-29.

58. British Cardiac Society; British Hypertension Society; Diabetes UK; HEART UK; Primary Care Cardiovascular Society; Stroke Association. JBS 2: Joint British Societies' guidelines on prevention of cardiovascular disease in clinical practice. Heart 2005;91 (Suppl 5):v1-52.

59. Goff D, Lloyd-Jones D, Bennett G, et al. 2013 ACC/AHA guideline on the assessment of cardiovascular risk: a report of the American College of Cardiology/American Heart Association task force on practice guidelines. J Am Coll Cardiol 2014;63(25 Pt B):2935-59.

60. Gasparini $C$, Sutherland H, Griffiths L. Studies on the pathophysiology and genetic basis of migraine. Curr Genomics 2013;14:300-15.

61. Lipton R, Bigal M. Migraine: epidemiology, impact and risk factors for progression. Headache 2005;45(Suppl 1):S3-13.

62. Rosamond W. Are migraine and coronary heart disease associated? An epidemiologic review. Headache 2004;44(Suppl 1):S5-12.
63. Miller D, Waters D, Warnica W, et al. Is variant angina the coronary manifestation of generalised vasospastic disorder? N Engl J Med 1981;304:763-6.

\section{Appendix 1 Exclusion reasons for 1814 papers}

Review (219), Case report (34), Letter (14), Webpage (5), Animal studies unrelated to Raynaud's phenomenon (RP) (4), Connective tissue disease (602), Vibration induced disease (169), Diagnosis/ investigation of RP (11), Secondary progression from primary RP (4), Drugs related to RP (53), RA/inflammatory arthritis (21), Other musculoskeletal (37), Fibromyalgia (9), Genetics not related to RP (11), Autoantibodies (13), Treatment involving sympathectomy (45), Ophthalmology studies (14), Psychiatric conditions (11), Haematological disease (14), Infectious disease (24), cardiovascular disease (64), Respiratory disease (17), Gastrointestinal disease (27), Renal disease (27), Dermatological (30), Endocrine disease (31), Neurological disease (43), Cancer (106), Drugs not related to RP (63), Vascular intervention (64), Laser Doppler flowmetry (8), Breast implant rupture (4), Others: including motor vehicles, dentists, seafarers, fishermen, aircrafts, breast feeding (17)

\section{Appendix 2 Exclusion reasons for 64 papers}

Letter to editor (1)

Review (5)

Diagnosis/Investigation of RP (14)

Secondary RP (39)

Treatment RP (1)

Same patient sample as is already included in another study used (3)

Case only study (1) 